\title{
A pesquisa científica
}

\author{
Scientific research
}

\section{Guilherme Benjamin Brandão Pitta1, Aldemar Araújo C astro²}

\begin{abstract}
Parainiciarmos uma pesquisa científica, devemos partir de três pré-requisitos básicos: 1) conhecer bem e ter competência no assunto a ser pesquisado; 2) ter acesso e dominar a amostra; e 3) depender o mínimo possível de terceiros para realizar a pesquisa. $D$ evemos também gostar do método científico e nos empolgar com 0 aprendizado que poderemos ter durante esse processo. A realização da pesquisa científica ea posterior publicação dos seus resultados em revista científica de impacto começam com a idéia brilhante que podemos ter a partir da pergunta de pesquisa que queremos responder. Por exemplo, se quisermos saber quais as características das válvulas venosas do segmento fêmoro-poplíteo (número deválvulas, de cúspides edisposição das mesmas), deveremos propor um trabalho científico para respondermos a essa questão.
\end{abstract}

$C$ ada pesquisa será composta de três fases: planejamento, execução e divulgação ${ }^{1}$. A primeira fase, 0 planejamento, é composta por cinco itens: a) idéia brilhante (a pergunta da pesquisa); b) plano deintenção (o resumo do projeto de pesquisa); c) revisão da literatura; d) teste de instrumentos e de procedimentos; e) projeto de pesquisa.

0 projeto de pesquisa deve incluir o título da pesquisa, dados de informação do autor e orientador, justificativa da pesquisa, hipótese, objetivo, plano de trabalho, métodos, etapas da pesquisa e cronograma, relação de materiais necessários, orçamento, monitori- zação da pesquisa, análise dos riscos e benefícios, propriedades da informação e divulgação da pesquisa, responsabilidades do pesquisador, da instituição, do promotor e do patrocinador, referências, modelo do termo de consentimento livre e esclarecido, modelo de formulários de coleta de dados, cópia do documento de aprovação pelo comitêde ética em pesquisa, modelo da tabela de dados individuais, curriculum vitae L attes dos pesquisadores envolvidos.

No projeto de pesquisa, é preciso ter cuidado especial em vários itens: 1) tipo de estudo - deve ser utilizado o melhor tipo de estudo para responder à pergunta de pesquisa; 2) local - onde estão os sujeitos da pesquisa; 3) amostra (critérios de inclusão, critérios deexclusão, amostragem, consentimento livreeesclarecido) - deve ser descrita com critérios objetivos, que representem com acuidade o universo de pacientes; 4) procedimentos- interven ção, teste, exposição, senecessário; 5) variáveis (variável primária, variáveis secundárias, dados complementares) - deve ser definida cada variável (como, quem) e quando será quantificada; 6) método estatístico (cálculo do tamanho da amostra, análiseestatística) - devem ser descritosos critériospara a definição do tamanho da amostra a ser estudada e quais serão os testes estatísticos a serem utilizados.

A amostra deve ser o mais homogênea possível, preferencialmente selecionada de acordo com critérios de inclusão e exclusão bem definidos. N os casos de 
divisão em grupos, estes devem ser constituídos sempre ao acaso, com o método de casualização bem definido. 0 delineamento envolve também a seleção cuidadosa dos desfechos e as variáveis a serem observadas². 0 planejamento deve incluir a análise por meio de testes estatísticos apropriados, para possibilitar conclusões pertinentes.

0 tempo e o trabal ho investidos no planejamento permitem que a segunda fase, que é a execução, seja feita sem problemas metodológicos e logísticos e transcorra sem nenhum imprevisto. N o entanto, a pesquisa só poderá ser iniciada após a aprovação pelo comitê de ética em pesquisa. A execução da pesquisa é finalizada com a redação do relatório final. $\mathrm{N}$ a terceira fase, a divulgação da pesquisa, devemos sintetizar as informações do relatório final eelaborar um artigo original para a comunidade de leitores e pesquisadores interessados no assunto ${ }^{3}$.

É obrigatória a publicação da pesquisa em uma revista científica, seja ela resultado de programa de iniciação científica, trabalho de conclusão de curso, dissertação de mestrado e/ou tese de doutorado. 0 J ornal Vascular B rasileiro éum bom veículo de divulgação em nosso meio, ea citação de artigos publicadosno nosso jornal ou em outras revistas produzidas no Brasil ena América L atina enriquece nossa produção científica e melhora o impacto da revista e sua visibilidade internacional. A publicação em revistaséa melhor, mais rápida e mais confiável forma de disseminar o conheci- mento científico no nosso meio e fora do nosso país, permitindo incluir nossa especialidade de angiologia e cirurgia vascular na comunidadeinternacional epreparando o ingresso da nossa revista na base de dados MEDLINE.

O Brasil, nosúltimosanos, vem aumentando sua publicação científica de impacto no mundo, e isso se deve principalmente ao aumento - em número e qualidade - das nossas pós-graduações stricto sensu, das nossas revistas científicas e dos portais de revistas da CAPES, Bireme e SciELO . Esse acesso rápido à informação através da I nternet, muito preciso e com custo diminuto, facilita sobremanei ra o trabal ho e dá condições aos pesquisadores de elaborar um bom projeto, que venha enriquecer os leitores da revista e melhorar o tratamento de nossos pacientes.

\section{R eferências}

1. Castro AA. Fiatlux. M aceió: U niversidadeEstadual deC iências da Saúde de Alagoas; 2006. Disponível em: http:// www.metodologia.org/livro.

2. Castro AA, coord. Programaminha primeirapesquisa. M aceió: U niversidadeEstadual deC iênciasda SaúdedeAlagoas; 2006. D isponível em: http://moodle.uncisal.edu.br.

3. Campana AO. Redação de trabalho científico. J Pneumol. 2000;26:30-5.

\section{Colega Associado da SBACV}

Você está convidado a participar do crescimento e consolidação do J Vasc Bras - como autor, leitor ou revisor.

Leia e divulgue; conheça as normas e submeta seus trabalhos.

\section{Jornal Vascular Brasileiro - Secretaria E ditorial}

Av. Protásio Alves, 1981 - sala 401

CEP 90410-002 - Porto Alegre, RS - Fone: (51) 3388.5000

E-mail: jvascbr@terra.com.br

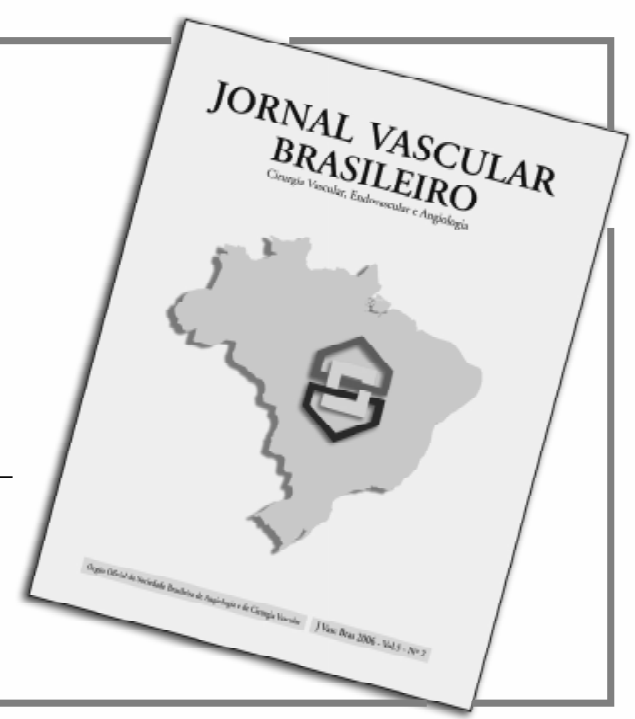

